\title{
AS RELAÇÕES DE PODER EM ESTUDO OBSERVACIONAL
}

\author{
R. F. MESQUITA ${ }^{1 *}$, S. N. O. SOUSA ${ }^{2}$ e F. R. N. MATOS ${ }^{3}$
}

${ }^{1}$ Instituto Federal de Educação, Ciência e Tecnologia do Piauí e Universidade de Fortaleza

${ }^{2}$ Universidade Federal do Piauí

${ }^{3}$ Universidade de Aveiro/Portugal

rafael.fernandes@ifpi.edu.br*

Artigo submetido em junho/2015 e aceito em dezembro/2015

DOI: $10.15628 /$ holos.2015.3156

\section{RESUMO}

Este trabalho objetiva analisar como se desenvolvem as relações de poder no filme "Django Livre" (2013). Assim, atende-se a este objetivo a partir de um estudo observacional, de abordagem metodológica qualitativa, em linguagem fílmica com observador não participante, e caráter teórico-empírico. Toma-se por base, principalmente, a abordagem sobre poder de Weber (1991), Lukes (1980), Foucault (2012) e Hard e Clegg (2001), destacando que as relações sociais estão permeadas por lutas pelo poder, sobretudo a dominação tradicional, o cerceamento e a disciplina. O tema foi escolhido a partir do filme "Django Livre", em que a escravatura é palco para o estudo das relações de poder naquela sociedade. Considera-se, finalmente, que o poder se manifesta, principalmente, através da tradição e poder econômico. A obediência não era a um estatuto, mas sim pessoal ao senhor. As relações estabelecidas se davam através do costume e que, ao tentar mudar a dinâmica do sistema, Django sofre violência física e a liberdade acontece diante da não mais aceitação daquela situação de disciplina e obediência.

PALAVRAS-CHAVE: Poder, Dominação, Obediência, Linguagem Fílmica.

\section{THE OBSERVATIONAL STUDY OF POWER RELATIONS}

\begin{abstract}
This work aims to analyze how the Power relations are developed in the movie "Django Free" (2013). We reached this goal from an observational study, qualitative methodological strategy in film language with nonparticipant observer, and theoretical and empirical approach. Takes as a basis primarily to approach power Weber (1991), Lukes (1980), Foucault (2012) and Hard and Clegg (2001), noting that social relations are permeated by power struggles, particularly domination traditional, retrenchment and discipline. The theme was
\end{abstract}

chosen from the film "Django Free" in which slavery is host to the study of power relations in that society. Finally considers that power manifests itself mainly through tradition and economic power. Obedience was not a statute, but rather personal to you. The relationships established through the usual give and that in trying to change the dynamics of the system, Django suffer physical violence and freedom happens in front of no more acceptance of that discipline and obedience situation.

KEYWORDS: Power, domination, obedience, film language. 


\section{INTRODUÇÃO}

O poder permeia todas as relações humanas em sociedade, ou seja, desde que haja dois homens já há uma relação de poder. Por isso, destaca-se a importância do estudo sobre o tema, mesmo diante da dificuldade de conceituá-lo e percebê-lo. "O conceito de poder é de tal maneira amplo que pode ser usado tanto para designar fenômenos sociais, relacionados à ação do ator social ou à prática social do homem, quanto fenômenos físico" (CARVALHO; VIEIRA, 2007, p. 3).

A definição de poder adotada neste trabalho baseia-se principalmente naquela de Weber (1991), em que há possibilidade de impor a vontade de A sobre B, mesmo havendo resistências contra tal. Este poder tem ainda duas dimensões: a dominação e a disciplina. Para a análise usamos a dominação tradicional fundamentada na crença de que as ordens dadas pelo senhor são sagradas. A dominação tradicional é baseada nos hábitos e costumes transferidos de geração para geração. Adota-se, também, a definição de Bourdieu (1998) de poder simbólico, pois o poder, muitas vezes, não é reconhecido, é invisível e é uma forma de integração social. O poder se dá através de símbolos que são instrumentos tanto do conhecimento como da comunicação.

O filme escolhido para análise é o "Django Livre" (2013) e relata a história do personagem "Django", escravo, que luta pela sua liberdade e de sua esposa. O fio condutor da história são as relações de poder no sistema escravocrata, ou seja, a relação dicotômica senhor-escravo. Nesta relação tradicional destaca-se o poder econômico do senhor, as constantes agressões físicas ao bel prazer do senhor e a obediência cega ao mesmo. A disciplina é impressionante, chegando ao ponto do personagem negro "Steven" castigar os outros negros e a chorar a morte de seu senhor.

Contudo, como essas relações de poder são desenvolvidas ao longo da trama? Como aspectos econômicos influenciam estas relações? Objetiva-se, neste estudo, analisar as relações de poder narradas em linguagem fílmica. Outros trabalhos já tiveram interesses similares, tais como Matos et al. (2011, p. 443), que afirmam que "o estudo das relações de poder sempre desafiou o homem", Mesquita et al. (2014a) enquanto analisavam as disputas de poder no campo científico e Machado et al. (2013) em estudo do exercício de poder formal aliado a práticas coercitivas, os três desenvolvendo análises em narrativas fílmicas.

A metodologia utilizada é de abordagem qualitativa, como método o estudo observacional em linguagem fílmica, onde o observador não participa do evento. É uma observação de "segunda mão", pois é feita através das imagens do filme. Para tanto, a observação seguiu passos criteriosos: definição do objetivo de pesquisa; a busca e seleção de fontes de dados narrativos, a escolha do filme; a visão geral da narrativa fílmica, realizada repetidas vezes; a decupagem dos dados; a fundamentação e interpretação teórica dos dados; e a edificação do relatório final.

A estrutura do artigo inicia com uma breve introdução, onde há explicação do objetivo do artigo e a sua relevância de aprofundamento teórico. Depois, seguem-se a seção de abordagem do poder, em que há uma discussão da categoria poder e, também, seus diferentes enfoques em outros trabalhos ao longo da história. Logo após, tem-se a seção aspectos metodológicos, com esclarecimentos sobre a metodologia utilizada e, a seguir, estudo observacional, em que o filme é analisado em conformidade com a bibliografia exposta neste trabalho. Por fim, as considerações finais e as referências bibliográficas. 


\section{ABORDAGENS DE PODER}

Sem desígnios de definir um conceito único e plenamente aceito de poder, fita-se desenvolver uma abordagem a partir dos diversificados enfoques que pesquisadores tais como Weber (1991), Foucault (2012), Lukes (1980), Maquiavel (2011) e outros, logo citados, discorrem em seus estudos. O ponto de partida é a concepção de poder que envolve critérios de significação, "útil para o entendimento das relações sociais", uma relação de consequências provocadas, "sem nenhuma restrição ao que tais consequências poderiam ser ou que as provoca" (LUKES, 1980, p. 825).

Para Weber (1991), o conceito de poder possui duas dimensões sem as quais as relações de poder não ocorrem: a dominação e a disciplina. Segundo o autor, o vocábulo poder não tem uma forma definida e as acepções de dominação e disciplina são mais precisas. Ele define os termos da seguinte forma:

Poder significa a probabilidade de impor a própria vontade numa relação social mesmo contra resistências, seja qual for o fundamento dessa probabilidade. Dominação é a probabilidade de encontrar obediência a uma ordem de determinado conteúdo, entre determinadas pessoas indicáveis; disciplina é a probabilidade de encontrar obediência pronta, automática e esquemática a uma ordem, entre uma pluralidade indicável de pessoas, em virtude de atividades treinadas (WEBER, 1991, p. 33).

A dominação é baseada no costume, nos interesses materiais e racionais, motivos afetivos ou racionais e, ainda, a crença na legitimidade. Esta, não é uma regra em todas as relações de poder, também, é somente uma probabilidade. A involuntariedade da obediência só ocorre no caso da escravidão, pois o escravo não tem como se negar a obedecer às ordens do senhor, diferentemente, por exemplo, na relação patrão-trabalhador. Portanto, "não se pode chamar 'dominação' enquanto não exista uma relação de obediência imediata, de forma que sejam dadas e controladas em sua execução instruções por sua direção, com a pretensão e a probabilidade de que sejam respeitadas pura e simplesmente como tais" (WEBER, 1991, p. 140).

Já a obediência é vista como se obedecer ao conteúdo de determinada ordem fosse para o dominado o correto, mesmo sem levar em consideração a sua própria opinião sobre a ordem dada. Segundo o autor, existem três formas de dominação legítima. A dominação racional, tradicional e carismática. Entretanto, para melhor esclarecer suas características, segue abaixo os conceitos das três formas:

1. De caráter racional: baseada na crença na legitimidade das ordens estatuídas e do direito de mando daqueles que, em virtude dessas ordens, estão nomeados para exercer a dominação (dominação legal), ou

2. De caráter tradicional: baseada na crença cotidiana na santidade das tradições vigentes desde sempre e na legitimidade daqueles que, em virtude dessas tradições, representam a autoridade (dominação tradicional), ou, por fim,

3. De caráter carismático: baseada na veneração extraordinária da santidade, do poder heroico ou do caráter exemplar de uma pessoa e das ordens por esta reveladas ou criadas (dominação carismática) (WEBER, 1991, p. 141). 
$\mathrm{Na}$ dominação tradicional, o dominado obedece ao senhor constituído pela tradição, hábitos e costumes. As ordens e o poder do senhor são vistos como sagrados. Obedece-se a um senhor pessoal e os dominados não são funcionários, mas sim submissos. Não há estatutos, o que existe é a pessoa do senhor estabelecida pela tradição. As ordens adquirem legitimidade de duas maneiras, a saber, de acordo com Weber (1991): primeiro, por causa da tradição que estabelece as ordens e sua não aceitação põe em risco todo o sistema; e ao livre arbítrio de que goza o senhor.

Esse livre arbítrio se dá na falta de limitações impostas ao senhor, onde, muitas vezes, ele é a própria lei. Deste modo, o senhor age de duas formas: ato ligado à tradição; e ato livre da tradição, onde, "o senhor pode manifestar 'benevolência', segundo livre arbítrio sobre graça ou desgraça, segundo simpatia ou antipatia pessoal e arbitrariedade puramente pessoal, particularmente comprável por presentes" (WEBER, 1991, p. 148). "O uso do poder é tão diversificado e multiforme. Os que usam o poder utilizam recursos que são relevantes para suas próprias necessidades, motivos e desejos, bem como necessidades, desejos e motivos daqueles que serão objeto de sua influencia" (KRAUSZ, 1991, p. 28).

Segundo Weber (1991), o quadro administrativo, ou seja, os servidores na dominação tradicional são: pessoas vinculadas ao senhor por elos de piedade (relações patrimoniais) membros do clã, escravos, funcionários domésticos dependentes, clientes, colonos, libertários; e relações extrapatrimoniais - relações pessoais de confiança, pacto de fidelidade com o senhor e funcionários livres. Ele enumera, ainda, as características que estão ausentes nesta relação:
a) a "competência" fixa segundo regras objetivas;
b) a hierarquia racional fixa;
c) a nomeação regulada por contrato livre e o ascenso regulado;
d) a formação profissional (como norma);
e) (muitas vezes) o salário fixo e (ainda mais frequentemente) o salário pago em dinheiro (WEBER, 1991, p. 149)

Na sociedade esse poder, muitas vezes, é simbólico, na concepção de Bourdieu (1998). Para ele, "o poder simbólico é, com efeito, esse poder invisível o qual só pode ser exercido com a cumplicidade daqueles que não querem saber que lhe estão sujeitos ou mesmo que o exercem" (BOURDIEU, 1998, pp. 7-8). Assim, na dominação tradicional o senhor e o (s) dominado (s) aceitam esta relação como legítima justificada pela tradição.

Símbolos são usados como forma de integração social (língua, mito, arte, dentre outros). Estes são máquinas do conhecimento e da comunicação e favorecem a manutenção da ordem social existente. A ideologia é usada a favor da classe dominante e faz parecer que seus interesses são, na verdade, o interesse comum. Ela favorece tanto a classe dominante como aos objetivos de quem a produz.

A cultura dominante contribui para a integração real da classe dominante (assegurando uma comunicação imediata entre todos os seus membros e distinguindo-os das outras classes); para a integração fictícia da sociedade no seu conjunto, portanto, à desmobilização (falsa consciência) das classes dominadas; para a legitimação da ordem estabelecida por meio do estabelecimento das distinções (hierarquias) e para a legitimação dessas distinções (BOURDIEU, 1998, p. 10). 
Já Bobbio (1998) afirma que o poder deve ser entendido de maneira geral e específica. De maneira mais geral, poder quer dizer competência para agir. E de forma específica, nas relações sociais, significa um homem influenciar as atitudes de outro homem. "Poder do homem sobre 0 homem. O homem não é só sujeito, mas também o objeto do Poder social" (BOBBIO, 1998, p. 933). O autor concorda com Weber ao dizer que o comportamento do dominado é voluntário e intencional, mesmo que inconscientemente. Na relação de escravidão, por meio da violência, o senhor obriga o escravo a obedecer à suas ordens e o escravo por medo da punição acaba por fazêlo. "Neste último caso, $A$ não modifica a conduta de $B$, mas modifica diretamente seu estado físico: mata-o, fere-o, imobiliza-o, aprisiona-o, etc" (BOBBIO, 1998, p. 935).

De tal modo, há várias bases de poder, elementos identificados como recursos que, em diferentes contingências fariam surgir o poder, tais como o capital, a especialidade técnica, acesso a contatos importantes, incerteza etc (HARDY; CLEGG, 2001). Não intentamos enumerar todas elas, ou mesmo todas as que poderiam ser identificadas no estudo observacional por interpretações diferentes, mas apontamos algumas que se apresentam suficientes para a análise do recorte proposto neste trabalho.

O domínio sobre a fonte de incerteza pode exercer um alto grau de poder, conforme Hardy e Clegg (2001) e, para corroborar a ideia, apresentamos o exemplo descrito pro Crozier (1964): operários da manutenção de máquinas possuíam um poder dominação sobre os trabalhadores da produção que as utilizavam, pois era necessário que as máquinas estivessem em pleno funcionamento, o que determinava que estes fossem dependentes dos trabalhadores da manutenção. Em consequência, esta habilidade de controlar incertezas determinava uma base de poder.

Outra base seria a inação, para promover uma inatividade política, o individuo pode ser enganado, trapaceado, coagido, influenciado ou manipulado. Estas definições estão associadas à ideia de uso do poder a fins de modelar as percepções, cognições e preferências destes indivíduos para que internalizem seu papel perante a sociedade, em uma ordem estabelecida pelos dominantes e, assim, não intuem alternativas, porque esta seria uma ordem natural das coisas. Neste sentido, Hardy e Clegg (2001, p. 269) apontam que "o poder de definir a realidade é usado pelas classes dominantes para apoiar e justificar sua dominação material, evitando, portanto, desafios a sua posição", esse tipo de autoridade exercida "simplesmente exige uma abstenção da ação" (LUKES, 1980, p. 837).

Outro conceito empregado é o de cerceamento, também relacionado à promoção da inação política. A classe dominante usa estratégias, para conter os espíritos revolucionários, a partir do controle do conhecimento das possibilidades de ação e, mesmo que os indivíduos as conheçam, também identificam facilmente as dificuldades de empreender no distúrbio à ordem, pois conhecem "demais a futilidade de tal ação" (HARDY; CLEGG, 2001, p. 270), dado que não dispõem dos meios ou recursos satisfatórios.

Assim, Lukes (1980) afirma que não há a necessidade de desordem, conflito ou revolução para que haja manifestação de poder, a sua própria ausência seria a determinação de uma classe dominante a uma dominada. Para isso o autor questiona, "não será o supremo exercício do poder evitar o conflito e a reivindicação influenciando, modelando e determinando as percepções e preferências de outros?" (1980, p. 870) O cerceamento é um bom exemplo desta prática. Todavia, 
a manifestação revolucionária é a forma mais frequente de tomada de poder, tal como caracteriza Maquiavel (2011, p. 59).

Deve, pois, um príncipe não ter outro objetivo nem outro pensamento, nem ter qualquer outra coisa como prática, a não ser a guerra, o seu regulamento e sua disciplina, porque essa não é a única arte que se espera de quem comanda. É ela de tanto poder que não só mantém aqueles que nasceram príncipes, mas muitas vezes faz com que cidadãos de condição particular ascendam àquela qualidade.

Nestes enfoques, a concepção de poder é assimétrica, conforme Lukes (1980, p. 826), elas "tendem a envolver conflitos e resistências", bem como as relações sociais e políticas são, predominantemente competitivas. Como características destas relações o autor identifica "o predomínio da vontade de alguns homens sobre a vontade de outros" e "supõe-se comumente que o poder deve envolver o uso de ameaça ou privações" (LUKES, 1980, p. 827). Há uma relação de dependência entre as classes ou indivíduos envolvidos e uma noção de poder como desigualdade, medida da capacidade de um obter vantagens sobre o outro.

Entra nesta abordagem, a compreensão de poder disciplinar de Foucault (2012, p. 164) que é, "com efeito, um poder que, em vez de se apropriar e retirar, tem como função maior 'adestrar' para retirar e se apropriar ainda mais e melhor. Ele não amarra as forças para reduzi-las; procura ligá-las para multiplicá-las e utilizá-las num todo". Assim, esta "disciplina 'fabrica' indivíduos; ela é a técnica específica de um poder que toma os indivíduos ao mesmo tempo como objetos e instrumentos de seu exercício". A disciplina auxilia na reprodução de padrões, a inação em contestar a ordem é mantida pela vigilância promovida por este tipo de poder.

Uma "anatomia política", que é também igualmente uma "mecânica do poder", está nascendo; ela define como se pode ter domínio sobre o corpo dos outros, não simplesmente para que façam o que se quer, mas para que operem como se quer, com as técnicas, segundo a rapidez e a eficácia que se determina. A disciplina fabrica assim corpos submissos e exercitados, corpos "dóceis". (FOUCAULT, 2012, p. 133).

Deste modo ela é usada, para o adestramento, ou como anteriormente citado, para o cerceamento e, por isso, ela é identificada como uma tecnologia em favor do estabelecimento do poder.

A disciplina não pode se identificar com uma instituição nem com um aparelho, ela é um tipo de poder, uma modalidade para exercê-lo, que comporta todo um conjunto de instrumentos, de técnicas, de procedimentos, de níveis de aplicação, de alvos; ela é uma "física" ou uma "anatomia" do poder, uma tecnologia. (FOUCAULT, 2012, p. 203).

Por mais que ela não se identifique com um ou outro aparelho, qual seja estatal ou privado, as instituições fazem uso de suas técnicas, pois, ainda conforme Foucault (2012, p. 204), "ela assegura uma distribuição infinitesimal das relações de poder" e as pessoas não seriam observadoras destas relações, ou mesmo somente seus atores sociais, mas "investidos de poder que nós mesmos renovamos, pois somos suas engrenagens" (FOUCAULT, 2012, p. 205). Assim como aqueles que fazem uso do poder "recorrem à posição, autoridade, pressão, manipulação, sedução, fundos, instituições, ideologias, prestígio, como também a suas capacidades e atributos 
pessoais de julgamento, comunicação, empatia, intuição etc, para mobilizar as pessoas a serem influenciadas" (KRAUSZ, 1991, p. 28).

Destacamos, assim, a importância do poder nas relações sociais. Carvalho e Vieira (2007) afirmam que na sociedade somente o amor tem tanta importância para os homens como o poder e declaram que até mesmo nas famílias e igrejas, instituições tradicionais, acontecem disputas de poder. Portanto, onde há relação entre dois homens há relações de poder. "As relações de poder permeiam toda a história humana e sempre foram relacionadas a algum tipo de superioridade, seja a força física, os meios econômicos ou o conhecimento, entre outros tantos" (MATOS et al., 2011, p. 443)

\section{ASPECTOS METODOLÓGICOS}

Ao ouvir estórias que as pessoas têm para contar, aprendemos sobre como certas vozes foram silenciadas, e sobre como se estabelecem resistências (HARDY; CLEGG, 2001, p. 283).

Ao adentrar o campo das relações sociais, das representações e dos seus significados exigese do pesquisador uma abordagem que possibilite uma investigação profunda e, para isso, as técnicas de pesquisa qualitativa seriam mais adequadas (MESQUITA et al., 2014b). Assim, tal como aclara Minayo (2007, p. 57), esta metodologia é a "que se aplica ao estudo da história, das relações, das representações, das crenças, das percepções e das opiniões, produto das interpretações que os humanos fazem a respeito de como vivem, constroem seus artefatos e a si mesmos, sentem e pensam".

Este enfoque qualitativo da pesquisa provê a investigação de uma apreciação mais apurada dos fenômenos sociais por buscar "estudar as coisas em seus cenários naturais, tentando entender, ou interpretar, os fenômenos em termos de significados que as pessoas a eles conferem" (DENZIM; LINCOLN, 2006, p. 17). O panorama é fictício, neste estudo, mas narra histórias envolvendo relações humanas, possibilitando sua análise e compreensão.

Aqui o observador é um tipo de espectador, nos moldes de Patton (2002), que assiste atentamente às relações desenvolvidas e seus significados, o que proporciona maior compreensão, bem como permite captar o contexto no qual as pessoas interagem. Além de ser um observador não participante, situação em que o investigador "pode não participar em absoluto, como quando ele se esconde atrás de uma tela que permite que ele veja os participantes, mas não permite que eles o vejam" (BECKER, 1997, p. 120).

Na perspectiva de Machado e Matos (2012, p. 4) "os filmes adquirem para si um encargo que ultrapassa as fronteiras da utilização didática, incorporando o papel de fontes de dados narrativos", assumindo o papel de lócus investigado com possibilidade de acessos repetidos e sem limites e, "por meio desses dados, tornando-se como que um espelho/reflexo da realidade a qual pertence o fenômeno ou objeto observado".

Para o estudo observacional em linguagem fílmica, Machado e Matos (2012) propõem alguns passos para sua consecução, são eles: a definição do problema ou objetivo de pesquisa; a busca e seleção de fontes de dados narrativos, a escolha do filme; a visão geral da narrativa fílmica, realizada repetidas vezes; a decupagem dos dados; a fundamentação e interpretação teórica dos dados; e a edificação do relatório final. 
Este tipo de metodologia vem sendo utilizado com frequência "pela sua grande capacidade de influência na realidade cotidiana, os filmes vêm sendo cada vez mais analisados em vista da sua utilização como instrumentos de pesquisa" (MACHADO; BEZERRA, 2010, p. 54), além de "facilitar a construção de um link entre construtos teóricos e realidade prática" (MATOS et al., 2011, p. 440) e a sua relevância "com a utilização de instrumentos da antropologia visual, por meio do estudo observacional, a fim de contribuir com os processos de ensino-aprendizagem no campo da Administração" (LEITE; LEITE, 2010, p. 77).

\section{ESTUDO OBSERVACIONAL}

Nesta seção é apresentada uma descrição sucinta das cenas do longa-metragem, com recorte dos principais acontecimentos e uma análise das cenas em paralelo com a fundamentação teórica exposta.

A história narrada no filme Django Livre (originalmente denominado Django Unchained) consiste em uma obra de fiç̧ão que relata um recorte de tempo onde a força de trabalho era mantida pela escravidão da população negra. O ano é 1858, dois anos antes da guerra civil. Na primeira cena do filme dirigido por Quentin Tarantino, escravos estão acorrentados e caminhando, durante o dia, em meio a pedras e formações rochosas, acompanhados por dois indivíduos montados a cavalo.

Durante o desenrolar da trama, aparecem repetidas vezes a frase "for your consideration" (para sua consideração - em tradução livre). Nesta cena, é a primeira vez que a frase aparece. Não há qualquer explicação sobre o significado desta frase na narrativa, mas acreditamos ser uma tentativa de chamar a atenção de quem assiste para cada cena e sua relevância no contexto geral do filme.

O cenário agora é noturno e a caminhada continua até que surge outro personagem, que se identifica como Doutor King Schultz, dentista, procurando por negociantes de escravos e esperando encontrar um escravo, especificamente, que residia na Fazenda Carrucan, Django, com quem conversa sobre a possibilidade de reconhecer um grupo de três homens que eram capatazes na referida fazenda.

O dentista atira nos dois homens que acompanhavam o grupo e leva Django consigo. Um dos homens permanece vivo e é atacado pelos escravos que permaneceram no local. Os dois seguem para uma cidade, onde são recebidos com olhares e comentários intrigados sobre o negro montado em um cavalo, imagem não usual para a sociedade à época. "Por que havia tão pouca resistência e por que esses grupos tão frequentemente consentiam em sua própria subjugação?" (HARDY; CLEGG, 2001, p. 267). A difícil tarefa de resistir ou modificar suas condições dependia de diversos fatores e isso se demonstra claramente neste cenário inicial.

Os dois entram em um bar e, novamente, Django não é bem recebido. O proprietário do estabelecimento corre buscando por ajuda quando o negro entra. Então, a sós, o dentista conversa com Django e expõe sua atual condição de caçador de recompensas por cadáveres de pessoas que é contratado, pelo governo, a matar. Um acordo é proposto à Django, sua liberdade e uma quantia em dinheiro em troca de encontrar os capatazes que o Doutor King Schultz está à procura e que o escravo conhece. "O poder tem sido visto tipicamente como a habilidade de fazer outros fazerem o que você quer que seja feito, se necessário contra a própria vontade deles" (HARDY; CLEGG, 
2001, p. 261) e "a capacidade potencial de influenciar as ações de indivíduos ou grupos no sentido de atuarem de uma determinada maneira" (KRAUSZ, 1991, p. 15). Nesta situação, o acordo é firmado e ambas as partes são favorecidas.

King Schultz mata o xerife da cidade em frente à população, o delegado é chamado e, após conversa, o dentista explica que assassinou um criminoso e conta sua história, apoiado por um documento oficial que apresenta à autoridade, um mandado emitido por um juiz, autorizando o homicídio. A cena seguinte retrata as intenções de Django. Em diálogo, ele fala sobre sua esposa, escrava que teve criação alemã, sobre como foram separados pelo antigo senhor que detinha sua propriedade e sua ambição de libertá-la.

"É contra a lei, crioulos a cavalo nesse território", diz o fazendeiro ao ver em sua porta Django e o dentista, que explica seu interesse em comprar uma das escravas da fazenda. A princípio o fazendeiro não se mostra interessado, mas o Dr. Schultz oferece uma quantia alta de dinheiro e o anfitrião convida-o a entrar. "As condições econômicas regulam o contexto no qual o trabalho é vendido e o capital levantado e, logo de início, duas classes são definidas: aqueles que possuem capital e aqueles que não o possuem" (HARDY; CLEGG, 2001, p. 263). O poder é um desses derivados das classes e das condições socioeconômicas.

King Schultz - Devo lembrá-lo que Django é livre e não pode ser tratado como escravo. Em nome das boas maneiras, ele deve ser tratado como eu.

Fazendeiro - Entendido, Schultz. Betina, Django não é um escravo, ele é livre. Não o trate como os crioulos daqui, pois ele não é igual. Entendeu?

Betina - O senhor quer que eu trate ele como um branco?

Fazendeiro - Não foi isso que eu disse.

O poder é mantido pelo cerceamento, os senhores procuram manter sua posição pela ignorância de seus dominados. "Enquanto todos os atores são, em alguma extensão, capturados pela rede dominante de relações de poder aqueles que se beneficiaram por essa condição estão, normalmente, em melhor posição para o desenvolvimento de estratégias que irão proteger suas posições" (HARDY; CLEGG, 2001, p. 280) e "o poder é onipresente na vida social. Os sistemas de poder sempre existiram e influenciaram a vida grupal e são parte inerente da experiência de cada ser humano. Portanto, seria fútil negar sua existência ou sua importância" (KRAUSZ, 1991, p. 12). Não tratar um escravo livre como um homem branco é mantê-lo em condição inferior.

Desde a mais tenra idade, os indivíduos sofrem pressões no sentido de se ajustarem à cultura do seu grupo e desenvolvem alternativas para lidar com o exercício de poder das pessoas e instituições que os rodeiam. Essa pressão social é que transforma cada ser humano em influenciador e influenciado, segundo os papéis que assume na arena social no decorrer de sua trajetória de vida, de acordo com as situações específicas em que se encontra (KRAUSZ, 1991, p. 17).

O poder disciplinar é outra ferramenta que auxilia neste controle, ele é, segundo Foucault (2012, p. 164), "com um efeito um poder que, em vez de se apropriar e de retirar, tem como função maior 'adestrar'; ou sem dúvida adestrar para retirar e se apropriar ainda mais e melhor". Sua função não é reduzir as forças, mas ligá-las e multiplicá-las para uso em seu favor. "A disciplina 
'fabrica' indivíduos; ela é técnica específica de um poder que toma os indivíduos ao mesmo tempo como objetos e como instrumentos de seu exercício".

Há, ainda, nesta situação narrada no filme, uma autoridade do senhor sobre o escravo, em que esta autoridade é, segundo Lukes (1980, p. 833), "a identificação do seu possuidor ou de quem a exerce como tendo direito a isso", este direito pode ser examinado através "das marcas ou sinais existentes em diferentes períodos históricos", como o da escravidão retratada, e "podem ser a idade, o gênero, a posição", aqui a casta de senhor.

\begin{abstract}
"Frequentemente, aqueles que têm relativamente menos poder permanecem assim por que são ignorantes sobre os caminhos do poder: ignorantes, assim, de questões de estratégia, tais como, conhecer os recursos do antagonista, os procedimentos de rotina, regras, estabelecimento de agendas, acesso, condutas informais, assim como protocolos formais, o estilo e a substância do poder. Não é que eles não conheçam as regras do jogo, o problema é que eles podem nem ao menos reconhecer o jogo, quanto menos conhecer suas regras. Muitas vezes, a ignorância estende-se a uma falta de conhecimento sobre outras agências menos poderosas com as quais poder-se-ia formar alianças". (HARDY; CLEGG, 2001, p. 269).
\end{abstract}

A manutenção da dominação tradicional é determinada por essas razões. "Em caso individual, a dominação 'autoridade' assim definida pode basear-se nos mais diversos motivos de submissão: desde o hábito inconsciente até considerações puramente racionais, referentes a fins". Mesmo que não haja vontade perceptível, a inconsciência da capacidade revolucionária ou mesmo a falta de anseio nesta direção. "Certo mínimo de vontade de obedecer, isto é, de interesse (externo ou interno) na obediência, faz parte de toda relação autêntica de dominação" (WEBER, 1991, p. 140). Assim como "um poder de punir que correria ao longo de toda a rede social, agiria em cada um de seus pontos, e terminaria não sendo mais percebido como poder de alguns sobre alguns, mas como reação imediata de todos em relação de cada um" (FOUCAULT, 2012, p. 126).

Django encontra, em seu passeio pela fazenda, aqueles que o dentista estava à procura. Mata dois deles com tiros e, após a chegada do Dr. Schultz, este mata o último, também a tiro. 0 fazendeiro chega e eles explicam o mandado emitido por um juiz que recompensava aquele que entregasse, vivos ou mortos, os três irmãos que acabaram de assassinar. Um grupo de pessoas liderado pelo fazendeiro monta uma emboscada para matar os dois caçadores de recompensa, mas caem em uma armadilha e, ao final, Django atira de uma longa distância, acerta e mata o líder do grupo.

Dr. Schultz admira a habilidade de seu companheiro e, conforme Hardy e Clegg (2001, p. 260), "o poder claramente deriva da propriedade e do controle dos meios de produção, apoiados pelo poder de vigilância. Importante, ainda, era o conhecimento, com o poder também derivado da perícia na utilização dos meios de produção", neste caso específico no uso de armas, "na maestria no exercício das atividades". O personagem tem sua participação garantida por estas habilidades, Dr. Schultz convida-o a continuar no negócio de caçar recompensas e garante a Django que o auxiliará na busca pela sua esposa após conseguirem mais recursos financeiros para compensar a tarefa. "É, numa boa proporção, como força de produção que o corpo é investido por relações de poder e de dominação; mas em compensação sua constituição como força de trabalho só é possível se ele está preso num sistema de sujeição" (FOUCAULT, 2012, p. 29). 
Eles continuam suas caçadas e Django é treinado por seu parceiro à desenvolver suas aptidões. Assim, conforme Hardy e Clegg (2001, p. 263), "considerando as diferentes possibilidades para a criatividade, torna-se claro que os membros da organização têm algum controle a sua disposição para exercer o poder." A criatividade para o exercício do poder pode ser expressa pelo desenvolvimento de suas habilidades e seu uso. "Desta forma, as estruturas de dominação da organização não dependem apenas do poder econômico para a sua constituição e permanência" (HARDY; CLEGG, 2001, p. 263), no mesmo sentido que "as relações de poder permeiam toda a história humana e sempre foram relacionadas a algum tipo de superioridade, seja a força física, os meios econômicos ou o conhecimento, entre tantos outros" (MATOS et al., 2011, p. 443).

Em conversa, Django e King Schultz desenvolvem uma estratégia para recuperar a esposa do primeiro, Broomhilda. Porém, o plano é bastante complicado, pois Django precisa interpretar o papel de um negro traficante de escravos, e ele afirma "não há nada mais baixo que um crioulo traficante de escravos". A dificuldade da ação consiste no poder que o título que pode impor. Um negro que negocia outros em mesma condição, por questões de cor, coloca-se no papel de um indivíduo que abominava: o negociante, capataz ou senhor a quem servia ou pertencia. Hardy e Clegg (2001, p. 263) corroboram esta afirmação ao colocar que há "opções e possibilidades de desafiar o poder que os controlava. Entretanto, como veremos, essas opções provaram estar longe de serem facilmente exercidas devido a estratégias mais sofisticadas por parte dos grupos dominantes".

Outro cenário e personagens são apresentados. Após descobrirem a fazenda onde a Broomhilda está, encontram seu proprietário em um local onde acontecem briga entre seus escravos. Espetáculos armados para diversão sua e de outros espectadores. Ao adentrarem o local, os dois companheiros são recebidos pelo advogado do fazendeiro Calvin Candie, o Sr. Leonide Moguy. Durante a interpretação de seu papel, Django contraria outras pessoas, usa expressões com atrevimento em direção as mesmas, sua condição, que seria similar a deles, o faz perceber-se igual e com tamanha liberdade.

Nem toda dominação se serve de meios econômicos. E ainda muito menos tem fins econômicos. Mas toda dominação de uma pluralidade de pessoas requer normalmente (não invariavelmente) um quadro de pessoas, isto é, a probabilidade (normalmente) confiável de que haja uma ação dirigida especialmente à execução de dispositivos gerais e ordens concretas, por parte de pessoas identificáveis com cuja obediência se pode contar. Esse quadro administrativo pode estar vinculado à obediência ao senhor (ou aos senhores) por costume ou de modo puramente afetivo, ou por interesses materiais ou por motivos ideais (racionais referentes a valores). (WEBER, 1991, p. 140).

Corroboramos a afirmação de Weber (1991), enquanto descrevemos os acontecimentos seguintes, apesar das condições econômicas formatarem uma situação determinante nas relações de poder. Django oferece uma quantia além do valor de mercado por um negro lutador e, assim, conseguem a confiança de Calvin Candie para entrarem em sua fazenda e prosseguir com o plano de recuperar Broomhilda. Mas é o personagem que interpreta que auxilia este processo. Ser negociantes de escravos torna-o convidado a participar do grupo em questão, formado somente por indivíduos nascidos livres e em melhor situação financeira. 
Django, a caminho da fazenda, a cavalo, pronuncia diversas ofensas aos escravos escoltados e, por isso, escuta um alarmante conselho de seu companheiro que estava preocupado em ter a farsa deles descoberta. Contudo, Django afirma que suas palavras mantém sua caracterização e intrigam o fazendeiro. "O poder faz o poder das palavras e das palavras de ordem, poder de manter a ordem ou de a subverter, é a crença na legitimidade das palavras e daquele que as pronuncia, crença cuja produção não é da competência das palavras" (BOURDIEU, 1998, p. 15). O simbolismo de sua posição garante este poder.

Os personagens chegam à fazenda e são recebidos pela família e de Calvin Candie e seu escravo mais antigo, Steven, que demonstra satisfação na chegada do seu senhor, mas não está tão agraciado por perceber Django, um negro montado a cavalo. "Muito mais do que tornar-se conhecido, o poder manifesta-se sem uma identificação clara, sem dizer a que veio" e "uma das principais artimanhas é imiscuir-se entre os homens sem ser percebido, de modo disfarçado e carregado de subterfúgios" (MATOS et al., 2011, p. 443). Steven questiona-se e a seu mestre sobre a presença do negro na casa principal e sobre o que sua família poderia pensar disso.

Steven é outro escravo que, em sua posição, tem alguns privilégios garantidos. Argumenta em favor do que acredita mesmo contra seu senhor, comanda punições a outros de sua casta e coordena as atividades da casa como se fosse um dos senhores de escravo e, "muito mais do que mostrar-se, o poder utiliza disfarces", a sentença de Matos et al. (2011, p. 443) amparam nossa compreensão desta relação. A participação ativa de Steven nos negócios da família e sua posição garantem este poder, mesmo que subjacente a alguns aspectos e sua liberdade não seja uma ambição ou mesmo uma vontade.

Django encontra sua esposa e inicia-se uma jornada em sentido de sua recuperação. Steven desconfia do plano e aconselha seu senhor sobre a negociação que tentam acordar, alertando-o. Calvin Candie acredita ter sido enganado e, em monólogo sobre sua vida na fazenda e a relação com negros escravos, questiona-se: "por que eles nunca tentaram nos matar"? O fazendeiro segue sua argumentação desabilitando as capacidades cognitivas dos indivíduos negros, pois acredita que estes são seres inferiores. "A disciplina fabrica assim corpos submissos e exercitados, corpos 'dóceis'." (FOUCAULT, 2012, p. 133). Não é a inferioridade de uma raça em relação à outra, mas o poder disciplinar que é exercido a fins de dominação.

Calvin Candie vende sua escrava ao Dr. King Schultz e entrega sua alforria, mas o acordo segue outras direções e as cenas seguintes à negociação são assim apresentadas, em ordem: o dentista mata o fazendeiro e é morto por um de seus capatazes; Django assassina diversos capatazes da fazenda, em tentativa de escapar do local, mas acabado sendo capturado e torturado. "A punição é uma técnica de coerção dos indivíduos; ela utiliza processos de treinamento do corpo - não sinais - com os traços que deixa, sob a forma de hábitos" (FOUCAULT, 2012, p. 126), tornouse habitual, um costume amplamente aceito e perpetuado o castigo a negros escravos, inclusive por Steven, escravo que explica como Django será punido em sua pena. À medida que "podemos concluir que o poder está presente em qualquer relacionamento e, para melhor compreender suas manifestações e consequências, é preciso considerar o contexto social e as características das pessoas envolvidas no processo de influenciar e ser influenciado" (KRAUSZ, 1991, p. 16).

Após Django conseguir escapar de sua prisão, o filme, em última cena, retrata a liberdade conquistada, o poder ser livre, adquirida pela destruição de outrem e, conforme Maquiavel (2011, p. 28) "não há garantia de posse mais segura que a ruína" e, ainda segundo o autor, a força adentra 
os campos onde a lei não permite sucesso de combate. Uma revolução de um só, um herói escravizado que se apoderou da competência atribuída às suas habilidades e virou o jogo das relações de poder entre o dominante branco, senhor, e o dominado, negro e escravo.

\section{CONSIDERAÇÕES FINAIS}

O artigo objetivou o estudo das relações de poder por meio de observação à linguagem fílmica em "Django Livre". A narrativa revela uma parte obscura da história mundial (escravidão) em que alguns se achavam superiores a outros. O senhor branco impõe sua vontade aos seus escravos como quiser, pois ele é a própria lei e os escravos são seus objetos. Neste sentido, Weber (1991, p. 148) afirma que "a natureza efetiva do exercício de dominação está determinada por aquilo que habitualmente o senhor (e seu quadro administrativo) podem permitir-se fazer diante da obediência tradicional dos súditos, sem provocar sua resistência". Quando há resistência, ela "dirige-se contra a pessoa do senhor (ou servidor) que desrespeitou os limites tradicionais do poder, e não contra o sistema como tal (revolução tradicionalista)".

O filme analisado traz consigo diversas possibilidades de interpretação, o que depende do enfoque que o pesquisador dá. Neste estudo, o personagem principal foi o foco das relações, que tinham como referência sua condição ao longo da trama. Assim, consegue-se visualizar as mudanças de atitude, o caráter socioeconômico das relações de poder e, principalmente, as consequências da exposição de uma figura negra, a cavalo, com trajes diferenciados e com poderio financeiro, em um contexto escravocrata. O conflito percebido amparou a compreensão dos significados destes símbolos às determinações das relações de poder.

O escravo negro, pelo menos o personagem principal, deixou de ser a figura submissa que tinha sua realidade constituída por outros sujeitos, enquanto dominadores e, ao longo do decurso dos fatos narrados, construiu seu espaço enquanto sujeito dominador, mesmo que apenas no cenário da fazenda em que a parte final da trama se desenvolve ou a cada vilarejo visitado, onde os matadores de aluguel executavam seu ofício.

Considera-se, enfim, que o poder se revela, especialmente, através da dominação tradicional, o que pode ser tornar também habitual, e poder econômico. A obediência não era a um estatuto, um conjunto de regimentos legais e normas, mas sim pessoal ao senhor, aspectos aclarados em diversos trechos da narrativa. As relações estabelecidas se davam através do costume e que, ao tentar modificar a dinâmica do sistema, Django sofre violência física, por meio de punições, e a liberdade acontece diante da não mais aceitação daquela situação de disciplina e obediência.

Vê-se, então, que todas as relações na sociedade são permeadas pelo poder. Ele está presente em todos os campos: na família, na escola, na igreja e nas organizações ou instituições em geral. Entretanto, não produz somente consequências negativas. "Temos que deixar de descrever sempre os efeitos de poder em termos negativos: ele 'exclui', 'reprime', 'recalca', 'censura', 'abstrai', 'mascara', 'esconde'. Na verdade, o poder produz; ele produz realidade; produz campos de objetos e rituais de verdade" (FOUCAULT, 2012, p. 185).

Destaca-se, finalmente, que o trabalho está longe de findar a discussão sobre poder e suas relações, ou mesmo as possibilidades de interpretação da realidade social nestes aspectos, à medida que a realidade ficcional apresentada também se insere neste contexto. $O$ tema, pela 
dificuldade de sua definição ou delimitação do seu campo, deve continuar a ser estudado. Desta forma, tem-se por último intuito contribuir para provocação de outros estudos sobre poder, suas relações, e o aprofundamento deste debate.

\section{REFERÊNCIAS}

1. BECKER, H. S. Métodos de pesquisa em ciências sociais. 3. ed. São Paulo: Hucitec, 1997.

2. вOBBIO, N. et al. Dicionário de política. 1. ed. Brasília: Editora Universidade de Brasília, 1998.

3. BOURDIEU, P. O poder simbólico. 2. ed. Rio de Janeiro, Bertrand Brasil, 1998.

4. CARVALHO. C. A.; VIEIRA, M. M. F. O poder nas organizações. São Paulo: Thomson Learning, 2007.

5. CROZIER, M. The bureaucratic phenomenon. Chicago: University of Chicago Press, 1964.

6. DENZIN, N. K.; LINCOLN. Y S. O planejamento da pesquisa qualitativa: teorias e abordagens. 2. ed. Porto Alegre: Bookman, 2006.

7. DJANGO LIVRE. Direção: Quentin Tarantino. Produção: Stacey Sher; Reginald Hudlin; Pilar Savone. Intérpretes: Jamie Foxx; Christoph Waltz; Leonardo DiCaprio; Kerry Washington; Samuel L. Jackson. Produção executiva: Harvey Weinstein; Michael Shamberg; Bob Weinstein. Direção de fotografia: Robert Richardson. Roteiro: Quentin Tarantino. Música: Luis Bacalov; Robb Boyd; Mary Ramos. Estados Unidos: Sony Pictures, 2013. 1 DVD (165 min). Widescreen, color., legendado.

8. FOUCAULT, Michel. Vigiar e Punir: nascimento da prisão. 40. ed. Petrópolis, RJ: Vozes, 2012.

9. HARDY, C.; CLEGG, S. R. Alguns ousam chamá-lo de poder. In: CLEGG, S. R.; HARDY, C.; NORD, W. R. (Org.). Handbook de estudos organizacionais. Volume 2. São Paulo: Atlas, 2001. (p. 260289).

10. KRAUSZ, R. R. Compartilhando o poder nas organizações. São Paulo: Nobel, 1991.

11. LEITE, N. R. P.; LEITE, F. P. A linguagem fílmica na formação e no fortalecimento de grupos, equipes e times de trabalho: aplicações do estudo observacional. REGE - Revista de Gestão da USP, v. 17, n. 1, pp. 75-97, 2010.

12. LUKES, S. Poder e autoridade. In: BOTTOMORE, T.; NISBET, R. História da análise sociológica. Rio de Janeiro: Zahar Editores, 1980. (p. 823-880).

13. MACHADO, D. Q.; BEZERRA, C. A. S. Avatar: uma análise dos aspectos fundamentais da terceirização em um estudo observacional. Revista Ibero-Americana de Estratégia - RIAE, v. 9, n. 3, p. 44-62, set./dez. 2010.

14. MACHADO, D. Q.; IPIRANGA, A. S. R.; MATOS, F. R. N. "Quero matar meu chefe": retaliação e ações de assédio moral. Pretexto, v. 14, n. 1, p. 52-70, jan./mar., 2013.

15. MACHADO, D. Q.; MATOS, F. R. N. (Org.). Estudos observacionais em linguagem fílmica. 1. ed. Curitiba, PR: CRV, 2012.

16. MAQUIAVEL, N. O príncipe. Rio de Janeiro: Nova Fronteira, 2011.

17. MATOS, F. R. N.; LIMA, A. C.; GIESBRECHT, C. M. Estudo observacional das relações de poder no filme O Óleo de Lorenzo. Cadernos EBAPE.BR, v. 9, n. 2, artigo 11, jun. 2011. 
18. MESQUITA, R. F.; SOUSA, L. R. M.; MATOS, F. R. N.; MILEN, A. F. Proposal of a Debate on Science and Power Relations in World War Z. Espacios, v. 35, n. 5, 2014a.

19. MESQUITA, R. F.; SOUSA, M. B.; MARTINS, T. B.; MATOS, F. R. N. Óbices metodológicos da prática de pesquisa nas ciências administrativas. Revista Pensamento Contemporâneo em Administração, v. 8, n. 1, p. 50-65, 2014b.

20. MINAYO, M. C. S. O desafio do conhecimento. São Paulo: Hucitec, 2007.

21. PATTON, M. Q. Qualitative research and evaluation methods. London: Sage Publications, 2002.

22. WEBER, M. Economia e sociedade: fundamentos da sociologia compreensiva. vol. 1. Brasília, DF: Editora Universidade de Brasília, 1991. 